[Agr. Biol. Chem., Vol. 26, No. 6, p. 378 386, 1962]

\title{
Hydrolysis Rate of Resistant Pentosan of White Birch Wood in Sulfuric Acid of Medium Strength
}

\author{
By Tatsuyoshi Kobayashi, Yoshio Sakai and Shinobu Mutoh \\ Faculty of Agriculture, Tokyo University of Education, Tokyo
}

Received February 24, 1962

\begin{abstract}
The purpose of this study is to find optimal conditions for pre-hydrolysis in the new wood saccharification process with strong sulfuric acid. In the experiment, the hydrolysis rate of resistant fraction of pentosan of white birch (Shirakamba, Betula platyphylla SukAtchev var. japonica HARA) wood and the decomposition rate of xylose are measured in acid concentrations ranging from 30 to $60 \%$ at temperatures ranging from 30 to $90^{\circ} \mathrm{C}$. The hydrolysis of resistant pentosan of white birch and the decomposition of xylose are the first-order reactions. The first-order reaction constant of hydrolysis of resistant pentosan, $k_{B} \min ^{-1}$, is expressed by the following empirical equations as the function of percentage concentration of sulfuric acid, $C$, and reaction temperature described by absolute temperature, $\mathrm{T}^{\circ} \mathrm{K}$, ranging from 40 to $80^{\circ} \mathrm{C}$ : $k_{B}=6.12 \times 10^{-7} \mathrm{G}^{6.49} \exp [-9160 /(R T)]$,

where sulfuric acid concentrations range from 30 to $50 \%$;

$$
k_{B}=5.04 \times 10^{5} \exp [-9160 /(R T)]
$$

where sulfuric acid concentration is $60 \%$.

The first-order reaction constant of decomposition of xylose, $k_{2} \min ^{-1}$, is expressed by the following empirical equation as the function of sulfuric acid strength described by acidity function, $H_{0}$, and reaction temperature described by absolute temperature, $T^{\circ} \mathrm{K}$, in sulfuric acid concentrations ranging from 30 to $60 \%$ at temperatures within the range of 40 to $100^{\circ} \mathrm{C}$.

$$
k_{2}=7.01 \times 10^{14} \exp [-1.39 C-31000 /(R T)] \text {, }
$$

where $C$ is sulfuric acid strength described by acidity function, $H_{0}$.
\end{abstract}

\section{INTRODUCTION}

The new process of wood saccharification with strong sulfuric acid ${ }^{1)}$ consists of three principal reaction stages and operations thereof.

Firstly, in the pre-hydrolysis, hemicellulose in wood chips is removed by the action of sulfuric acid of medium strength.

Secondly, the centrifugal separation of pre-hydrolyzed wood chips from sulfuric acid controls the mixing ratio of sulfuric acid to dry wood in main-hydrolysis described

1) T. Kobayashi, presented before the Second Meeting of the Working Party on Wood Hydrolysis, FAO Technical Panel on Wood Ghemistry, held in Tokyo, Japan, 1960. below.

Thirdly, in a continuous through-circulation dryer, air or dry air blows at $45 \sim 65^{\circ} \mathrm{C}$ through a bed of pre-hydrolysis residues consisting of celulose, lignin and sulfuric acid of medium strength. During this process ${ }^{2)}$ sulfuric acid is concentrated and the concentrated sulfuric acid converts cellulose into soluble glucose polymer which is soluble in water and easily hydrolyzed in dilute acid ${ }^{3)}$. This process is called main-hydrolysis.

Fourthly, in countercurrent extraction, the

2) T. Kobayashi, K. Mitachi, K. Kikuchi and Y. Kamiyama, This Journal, 26, 371 (1962)

3) T. Kobayashi and Y. Sakai, ibid., 22, 117, 277 (1958). 
soluble in main-hydrolysis product is washed. The soluble contains soluble glucose polymer and sulfuric acid.

Fifthly, the recovery of sulfuric acid from the extract by a dialysis method ${ }^{4}$ is carried out. Sulfuric acid recovered is readily adapted for reuse in further pre-hydrolysis process.

Sixthly, the post-hydrolysis in which the glucose polymer can be easily hydrolyzed by undialyzed sulfuric acid is undertaken.

In the new wood saccharification process using a strong sulfuric acid solution, experiments for finding optimal conditions of prehydrolysis have been desired since information on this subject has been hardly available in the literatures concerning wood saccharification.

The present paper deals with the kinetics of hydrolysis of pentosan in white birch wood in a sulfuric acid solution of medium strength ranging from 30 to $60 \%$ at temperatures ranging from 30 to $90^{\circ} \mathrm{C}$.

\section{MATERIALS AND METHODS}

Samples of white birch wood (shirakamba, Betula platyphylla Sukatchev var. japonica HARA) ground to small pieces (20 to 40 mesh) were subjected to hydrolysis. The oven-dry sample contained $23.9 \%$ pentosan, $72.8 \%$ potential reducing sugar, and $22.6 \%$ lignin.

The method by which the present experiment was conducted was similar to the procedure described in a previous report ${ }^{5}$. The method of analysis used in this work was also similar to the method described in the said previous report. Pentose and pentosan were determined by a colorimetric method using benzidine ${ }^{(3)}$, reducing sugar by Somogyi's method ${ }^{\text {r) }}$ and potential reducing sugar by the method of Saeman, Bubl and Harris ${ }^{\text {s). }}$

4) I. Karaushi and T. Matsuno, Report of the Hokkaido Forest Products Research Institute, No. 15, 64 (1959); E. Tanaka and T. Kuwata, ibid., No. 15, 106 (1959).

5) T. Kobayashi and Y. Sakai, This Journal, 20, 1 (1956).

6) Y. Sakai, J. Agr. Chem. Soc. Japan, 30, 256 (1956).

7) M. Somogyi, J. Biol. Chem., 160, 61 (1945).

8) J.F. Saeman, J.L. Bubl and E.E. Harris, Ind. Eng. Chem., Anal. Ed., 17, 35 (1945).

\section{RESULTS AND DISCUSSION}

Hydrolysis Rate of Pentosan Difficult to Hydrolyze. After the sample of white birch wood was subjected to the measurements of extent of hydrolysis under various conditions, the loga-

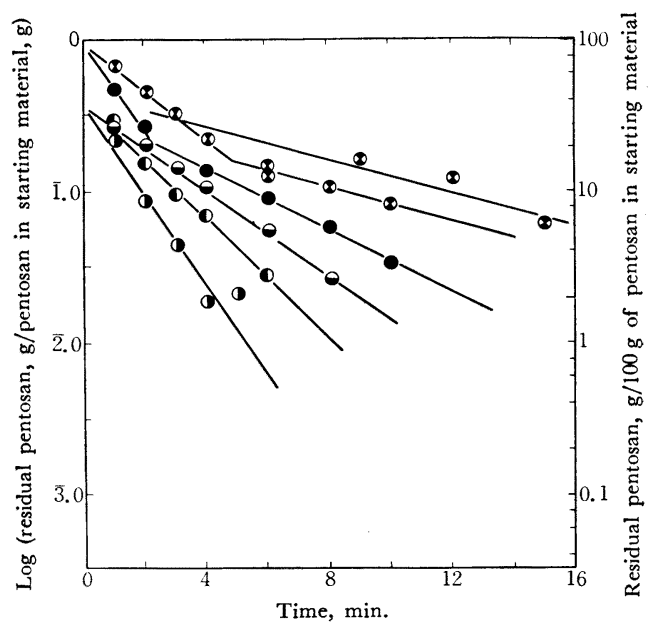

FIG. 1. Hydrolysis of Hardwood Pentosan in $60 \%$ Sulfuric Acid at Different Temperatures.
(D) $70^{\circ} \mathrm{C}$
() $60^{\circ} \mathrm{C}$
- $50^{\circ} \mathrm{C}$
- $40^{\circ} \mathrm{C}$
$30^{\circ} \mathrm{C}$

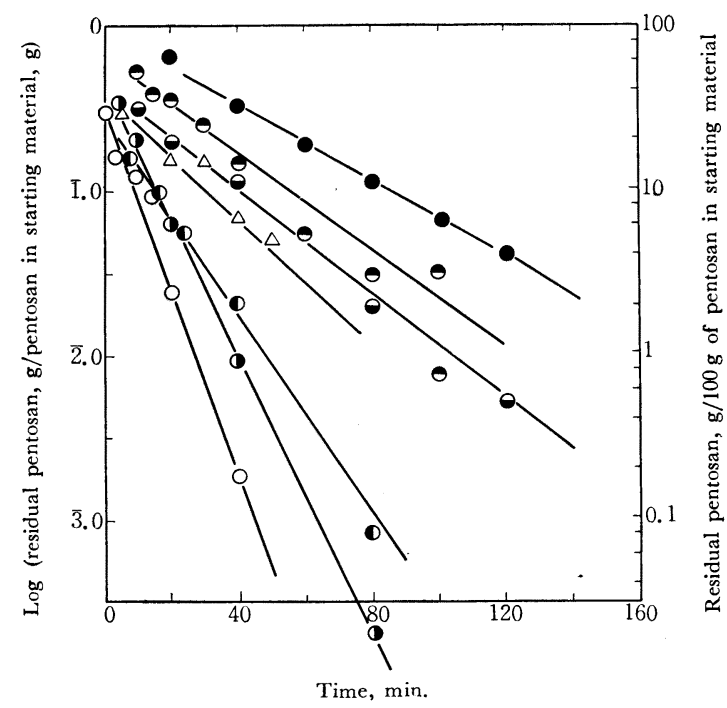

FIG. 2. Hydrolysis of Hardwood Pentosan in 50\% Sulfuric Acid at Different Temperatures.
$80^{\circ} \mathrm{C}$
- $50^{\circ} \mathrm{C}$
(1) $70^{\circ} \mathrm{C}$
(1) $60^{\circ} \mathrm{C}$
$\triangle 53^{\circ} \mathrm{C}$ 


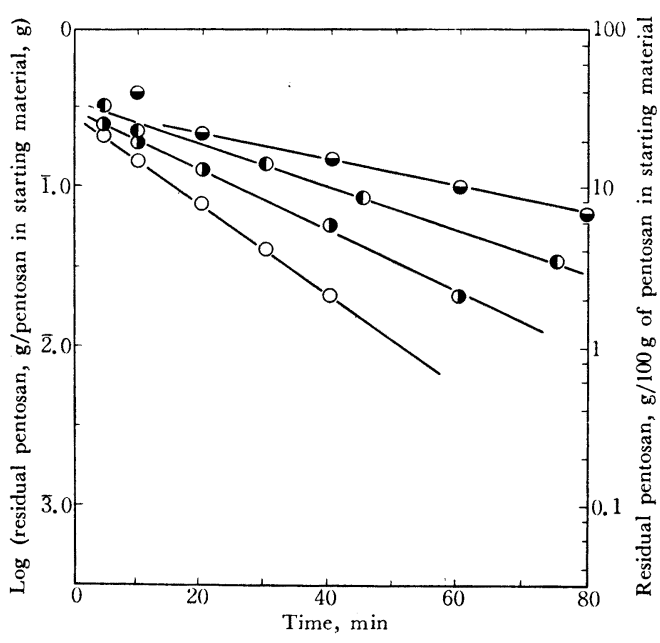

FIG. 3. Hydrolysis of Hardwood Pentosan in $45 \%$ Sulfuric Acid at Different Temperatures.

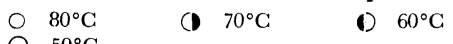

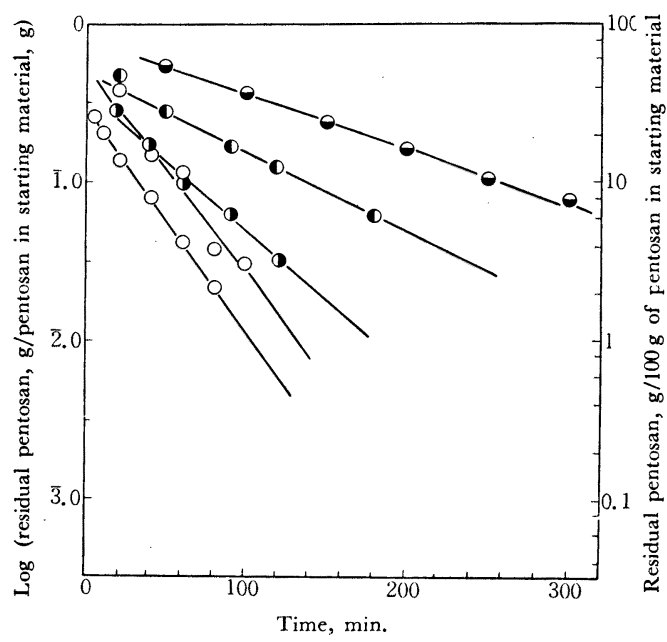

FIG. 4. Hydrolysis of Hardwood Pentosan in $40 \%$ Sulfuric Acid at Different Temperatures.

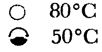
(1) $70^{\circ} \mathrm{C}$
1) $60^{\circ} \mathrm{C}$

rithms of the ratios of residual potential pentose to initial potential pentose were plotted against time in minutes as shown in Figs. 1 to 6 . These figures show that the pentosan hydrolysis is the first-order reaction. The reaction constants are obtained

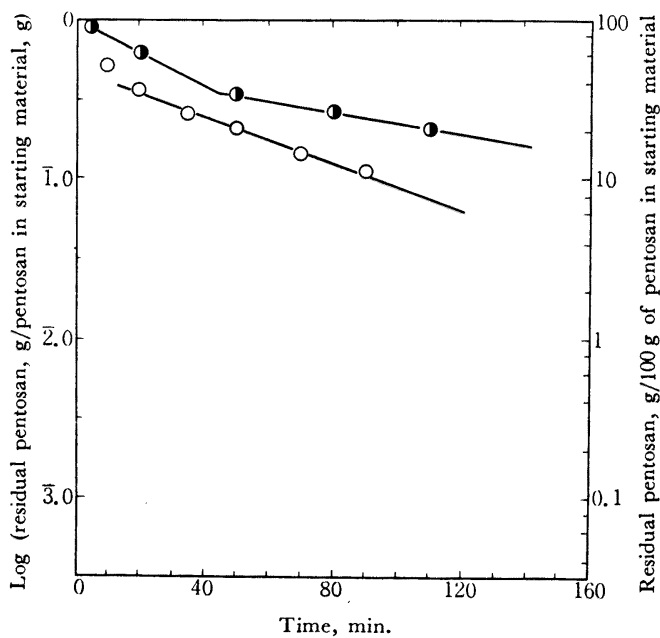

FIG. 5. Hydrolysis of Hardwood Pentosan in $35 \%$ Sulfuric Acid at $70^{\circ}$ and $80^{\circ} \mathrm{C}$

○ $80^{\circ} \mathrm{C}$ o $70^{\circ} \mathrm{C}$

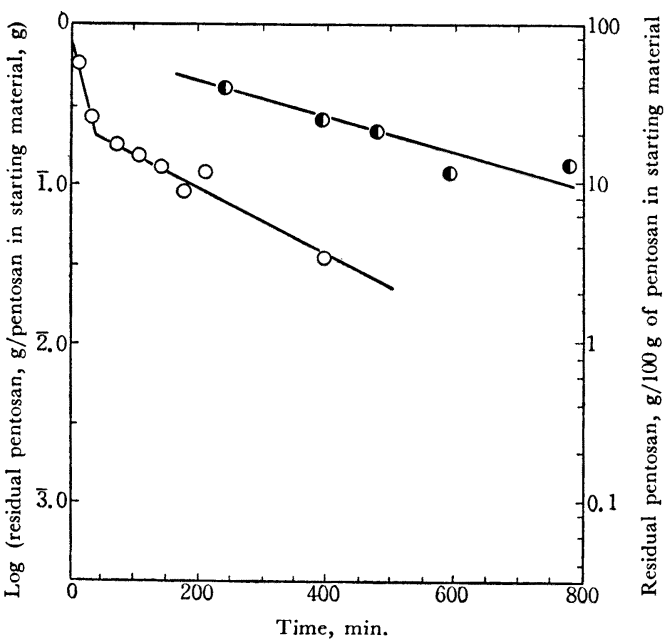

Fig. 6. Hydrolysis of Hardwood Pentosan in $30 \%$ Sulfuric Acid at $60^{\circ}$ and $80^{\circ} \mathrm{C}$.

$$
\text { ○ } 80^{\circ} \mathrm{C} \quad 60 \mathrm{C}^{\circ}
$$

by multiplying the slopes of these lines by 2.303. The extrapolation of these lines to zero time of reaction does not pass through the point representing the initial potential pentose. Two lines having different slopes are observed with the lapse of time in the 
pentosan hydrolysis as shown in Figs. 1, 5 and 6. This result agrees with the authors' previous experiments ${ }^{5}$. The notation $k_{B}$ $\min ^{-1}$ is used in the description of reaction constant of hardly hydrolyzable pentosan fraction of white birch wood. The reaction constants, $k_{B}$, in a sulfuric acid solution ranging from 30 to $60 \%$ in concentration at temperatures ranging from 30 to $80^{\circ} \mathrm{C}$ are summarized in Table $\mathrm{I}$.

TABLE I. HydRolysis Rate Constants OF White BIRCH WOOD PENTOSAN DIFFICULT TO HYDROLYZE IN SUlfuric ACID OF MEdium STRENGTH

\begin{tabular}{|c|c|c|c|}
\hline \multirow{2}{*}{$\begin{array}{l}\mathrm{H}_{2} \mathrm{SO}_{4} \\
\text { concn. } \\
\%\end{array}$} & \multirow{2}{*}{$\underset{{ }^{\circ} \mathrm{C}}{\text { Temp. }}$} & \multicolumn{2}{|c|}{$\begin{array}{l}\text { 1st-order reaction constant, } \\
k_{B}\left(\min ^{-1} .\right)\end{array}$} \\
\hline & & Obsvd. & Calcd.* \\
\hline 60 & $\left\{\begin{array}{l}70 \\
60 \\
50 \\
40 \\
30 \\
30\end{array}\right.$ & $\begin{array}{l}0.663 \\
0.458 \\
0.326 \\
0.237 \\
0.110 \\
0.128\end{array}$ & \\
\hline 50 & $\begin{array}{l}80 \\
70 \\
60 \\
53 \\
50 \\
45 \\
40\end{array}$ & $\begin{array}{l}0.137 \\
0.106 \\
0.0644 \\
0.0447 \\
0.0374 \\
0.0346 \\
0.0263\end{array}$ & $\begin{array}{l}0.138 \\
0.0914 \\
0.0631 \\
0.0457 \\
0.0398 \\
0.0331 \\
0.0265\end{array}$ \\
\hline 45 & $\begin{array}{l}80 \\
70 \\
60 \\
50\end{array}$ & $\begin{array}{l}0.0660 \\
0.0443 \\
0.0292 \\
0.0204\end{array}$ & $\begin{array}{l}0.0697 \\
0.0440 \\
0.0318 \\
0.0200\end{array}$ \\
\hline 40 & $\begin{array}{l}80 \\
80 \\
70 \\
60 \\
50\end{array}$ & $\begin{array}{l}0.0311 \\
0.0334 \\
0.0208 \\
0.0148 \\
0.00803\end{array}$ & $\begin{array}{l}0.0324 \\
0.0324 \\
0.0214 \\
0.0114 \\
0.00931\end{array}$ \\
\hline 35 & $\left\{\begin{array}{l}80 \\
70\end{array}\right.$ & $\begin{array}{l}0.0108 \\
0.00812\end{array}$ & $\begin{array}{l}0.0137 \\
0.00904\end{array}$ \\
\hline 30 & $\begin{array}{l}80 \\
60\end{array}$ & $\begin{array}{l}0.00541 \\
0.00274\end{array}$ & $\begin{array}{l}0.00502 \\
0.00240\end{array}$ \\
\hline
\end{tabular}

When the logarithms of the reaction rate constants are plotted against the logarithms of the percentage concentrations of sulfuric acid, parallel straight lines are obtained in intervals proportional to the reciprocals of absolute temperatures within the range of sulfuric acid concentrations of 30 to $50 \%$ (Fig. 7). The slope of these lines is 6.49.
The reaction constant in $60 \%$ sulfuric acid deviates from the straight lines described above, as shown in Fig. 7. It seems that the reaction of pentosan in $60 \%$ sulfuric acid

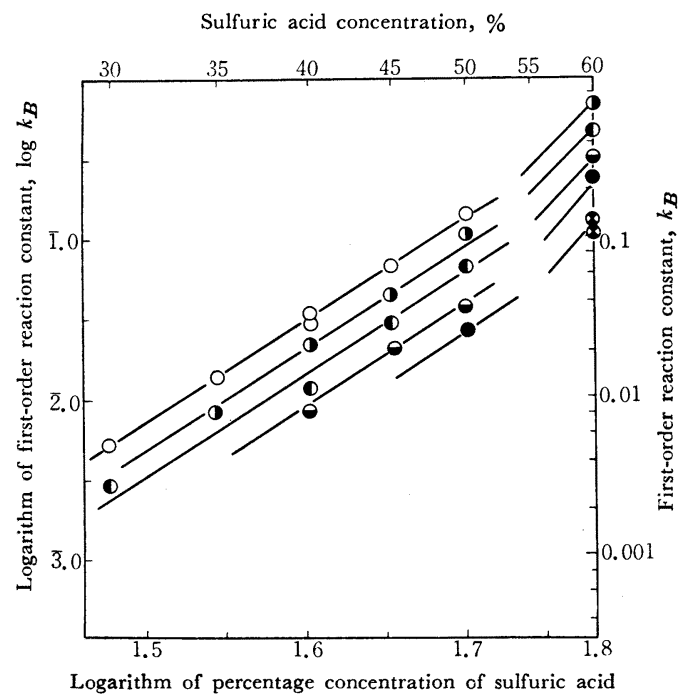

FIG. 7. Relation of First-order Reaction Constant to Sulfuric Acid Concentration in Hydrolysis of Hardwood Pentosan at Different Temperatures.

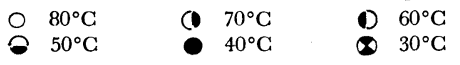

differs from those in $50 \%$ or less acid strength. This is in line with the fact that the mode of reaction of sulfuric acid of $60 \%$ or more concentration on cellulose differs from that of the acid lower than $56 \%$ in concentration. When the logarithms of these reaction constants are plotted against the reciprocals of absolute temperatures, parallel straight lines are obtained in intervals proportional to the logarithms of percentage concentrations of sulfuric acid. The activation energy calculated from the slope of these lines is 9160 $\mathrm{cal} / \mathrm{mol}$ (Fig. 8). Using the equation presented by Saeman ${ }^{9)}$, the experimental equation describing the first-order reaction constant in hydrolysis of hardly hydrolyzable pentosan of white birch wood, $k_{B}$, is calcu-

9) J.F. Saeman, Ind. Eng. Chem., 37, 43 (1945). 


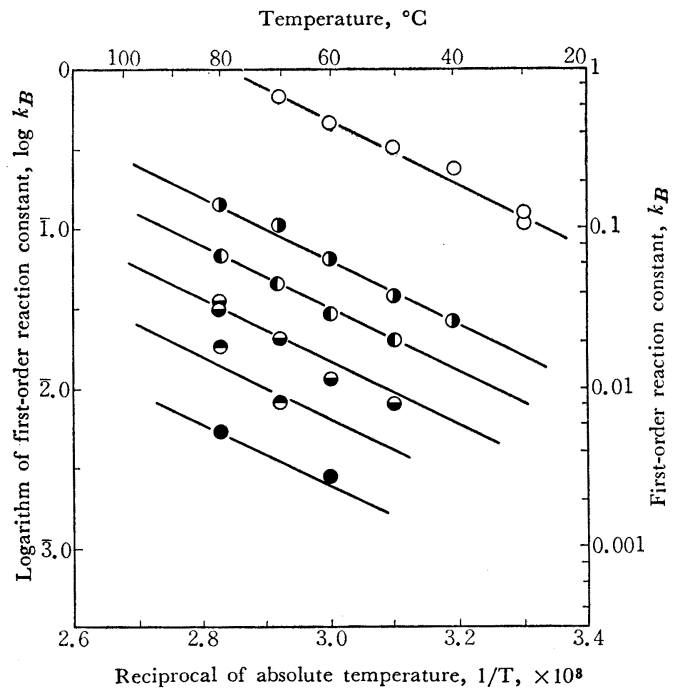

FIG. 8. Relation of First-order Reaction Constant to Temperature in Hydrolysis of Hardwood Pentosan in Sulfuric Acid of Different Concentrations.

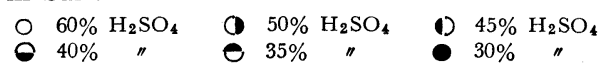

lated as follows: In sulfuric acid concentrations ranging from 30 to $50 \%$ within the range of temperatures of 30 to $80^{\circ} \mathrm{C}$,

$$
k_{B}=6.12 \times 10^{-7} \mathrm{C}^{6.49} \exp [-9160 /(R T)] \text {, }
$$
in $60 \%$ sulfuric acid within the range of temperatures of 30 to $60^{\circ} \mathrm{C}$,

$$
k_{B}=5.04 \times 10^{5} \exp [-9160 /(R T)] \text {, }
$$

where $C$ is percentage concentration of sulfuric acid, $R$ gas constant and $T$ absolute temperature, ${ }^{\circ} \mathrm{K}$.

Hydrolysis of Hexosan. Hydrolysis of pentosan was accompanied with hydrolysis of hexosan to some extent as the reaction time was extended. Hexosan content of the sample was obtained by subtracting its potential pentose content from its potential reducing sugar content. When the percentages of residual hexosan were plotted against time in minutes, concave curves were obtained as shown in Figs. 9 to 12 . These curves show that the loss of hexosan during pentosan hydrolysis is inevitable except that the loss in $40 \%$ sulfuric acid at $50^{\circ} \mathrm{C}$ is negligible.

Decomposition Rate of Xylose. The decomposition rate of xylose in sulfuric acid of medium strength was also observed. An

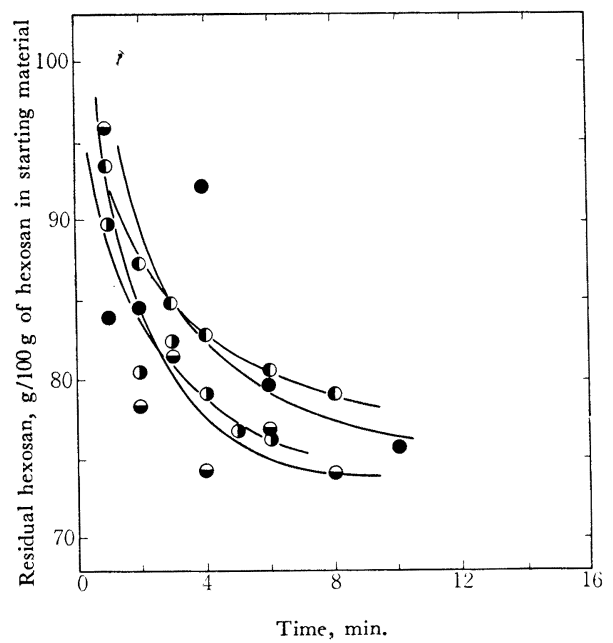

FIG. 9. Hydrolysis of Hardwood Hexosan in $60 \%$ Sulfuric Acid at Different Temperatures.

(1) $70^{\circ} \mathrm{C} \quad$ D $60^{\circ} \mathrm{C} \quad \odot 50^{\circ} \mathrm{C}$

- $40^{\circ} \mathrm{C}$

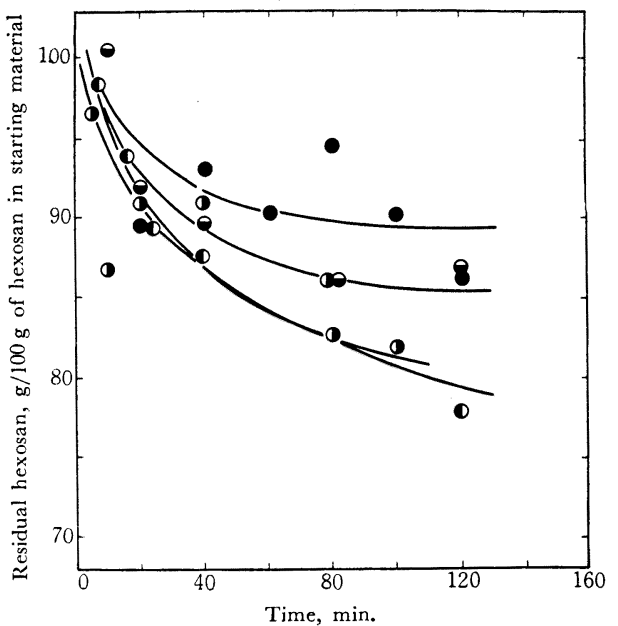

FIG. 10. Hydrolysis of Hardwood Hexosan in 50\% Sulfuric Acid at Different Temperatures.

(1) $70^{\circ} \mathrm{C} \quad \odot 60^{\circ} \mathrm{C} \quad \odot 50^{\circ} \mathrm{C}$ 


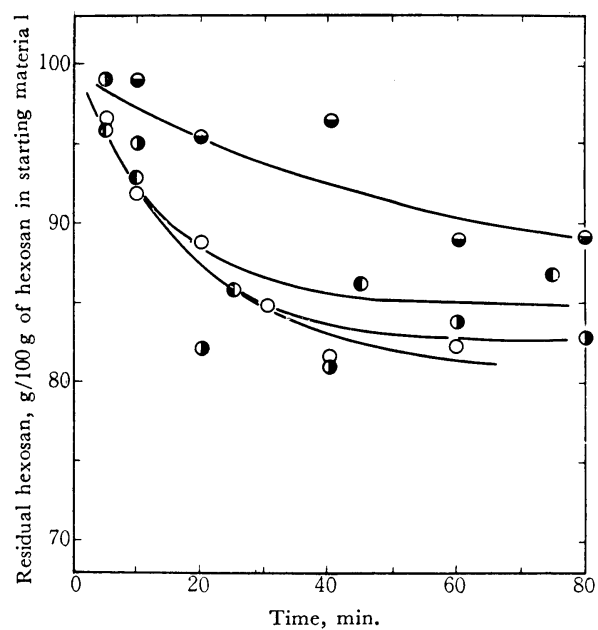

FIG. 11. Hydrolysis of Hardwood Hexosan in $45 \%$ Sulfuric Acid at Different Temperatures.
$\stackrel{\circ}{\odot} 50^{\circ} \mathrm{C}$
(1) $70^{\circ} \mathrm{C} \quad 060^{\circ} \mathrm{C}$

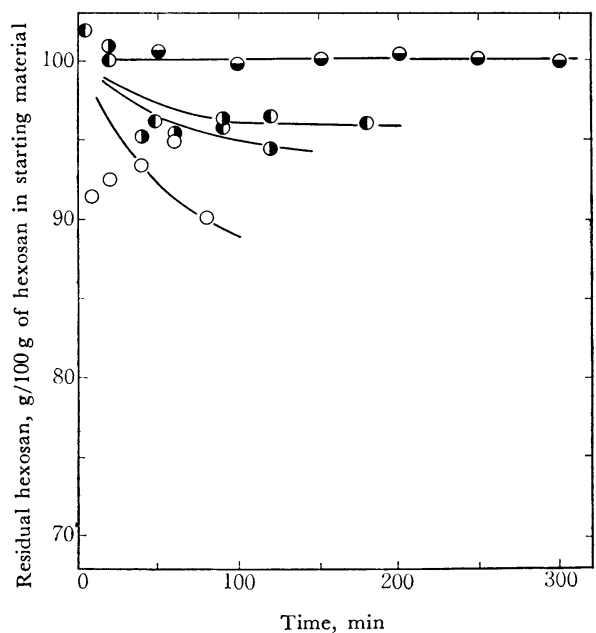

FIG. 12. Hydrolysis of Hardwood Hexosan in $40 \%$ Sulfuric Acid at Different Temperatures.

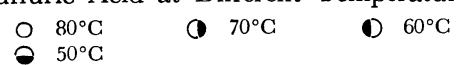

example of the results is given in Fig. 13. The straight line indicates that the reaction is of the first-order. The first-order reaction constants measured under various conditions are summarized in Table II.

When the logarithms of the first-order re-

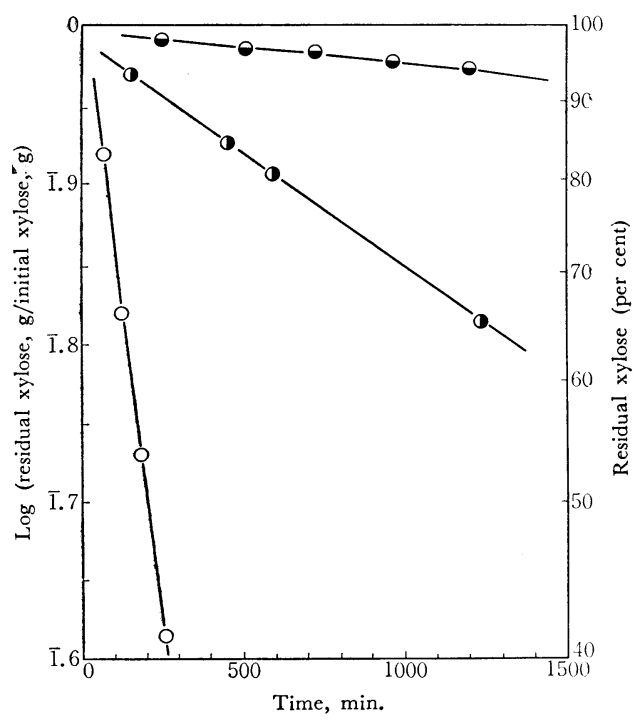

FIG. 13. Decomposition of Xylose in 50\% Sulfuric Acid at 45,61 and $80^{\circ} \mathrm{C}$.
○ $80^{\circ} \mathrm{C}$
(1) $61^{\circ} \mathrm{C}$
- $45^{\circ} \mathrm{C}$

TABle II. Rates of Destruction OF Xylose IN SUlfuRIC ACID OF MEdIUM STRENGTH

\begin{tabular}{|c|c|c|c|c|}
\hline \multirow{2}{*}{$\underset{\%}{\mathrm{H}_{2} \mathrm{SO}_{4}}$} & \multirow{2}{*}{$\begin{array}{c}\text { Concn. } \\
\mathrm{H}_{0}\end{array}$} & \multirow{2}{*}{$\underset{{ }^{\circ} \mathrm{C}}{\text { Temp. }}$} & \multicolumn{2}{|c|}{$\begin{array}{l}\text { 1st-Order reaction } \\
\text { constant, min. }^{-1}\end{array}$} \\
\hline & & & Obsvd. & Calcd.* \\
\hline 60 & -4.32 & $\left\{\begin{array}{l}80 \\
45\end{array}\right.$ & $\begin{array}{l}0.0193 \\
0.000148\end{array}$ & $\begin{array}{l}0.0190 \\
0.000146\end{array}$ \\
\hline 50 & -3.32 & $\begin{array}{l}80 \\
61 \\
45\end{array}$ & $\begin{array}{l}0.00343 \\
0.000320 \\
0.0000460\end{array}$ & $\begin{array}{l}0.00408 \\
0.000335 \\
0.0000330\end{array}$ \\
\hline 46 & -2.82 & 61 & 0.000221 & 0.000189 \\
\hline 40 & -2.28 & $\left\{\begin{array}{r}100 \\
80 \\
61\end{array}\right.$ & $\begin{array}{l}0.0151 \\
0.00116 \\
0.000093\end{array}$ & $\begin{array}{l}0.0113 \\
0.00109 \\
0.0000893\end{array}$ \\
\hline 30 & -1.54 & $\left\{\begin{array}{r}100 \\
80 \\
61\end{array}\right.$ & $\begin{array}{l}0.00403 \\
0.000407 \\
0.0000193\end{array}$ & $\begin{array}{l}0.00404 \\
0.000388 \\
0.0000319\end{array}$ \\
\hline
\end{tabular}

* Calculated from $k_{2}=7.01 \times 10^{14} \exp \left[-1.39 \mathrm{H}_{0}-31000 /(R T)\right]$

action constants in Table II are plotted as the function of acidity function, $H_{0}$, parallel straight lines are obtained in intervals corresponding to reciprocals of absolute tem. peratures as shown in Fig. 14. When the logarithms of the reaction constants are plotted against the reciprocals of absolute temperatures, parallel straight lines are ob- 
tained at intervals corresponding to the acidi-

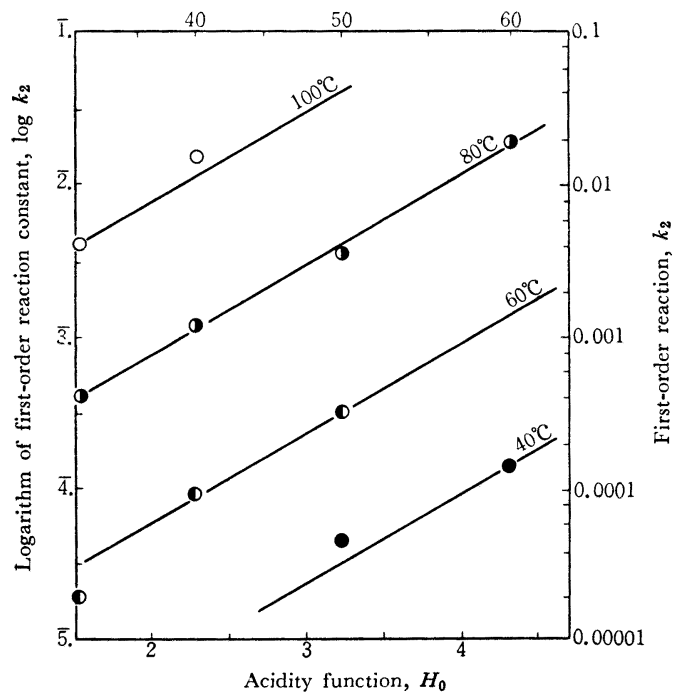

FIG. 14. Relation of First-order Reaction Constant to Sulfuric Acid Strength in Decomposition of Xylose at Different Temperatures.

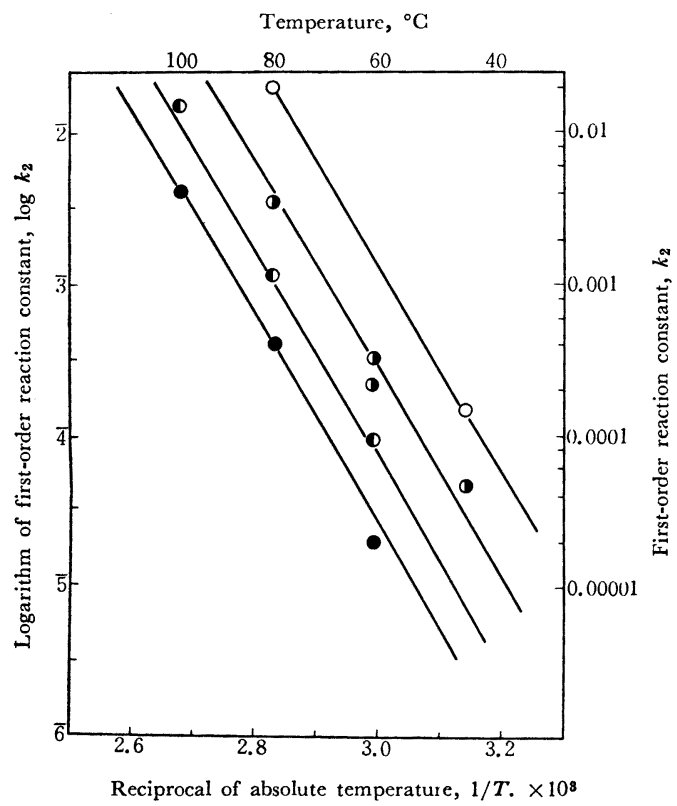

FIG. 15. Relation of First-order Reaction Constant to Temperature in Decomposition of Xylose in Sulfuric Acid of Different Strengths.

○ $60 \% \mathrm{H}_{2} \mathrm{SO}_{4}$ - $50 \% \mathrm{H}_{2} \mathrm{SO}_{4}$ ○ $60 \% \mathrm{H}_{2} \mathrm{SO}_{4}$ - $30 \%$ ty function as shown in Fig. 15. These facts indicate that the following equation fits well the first-order reaction constants in decomposition of xylose in sulfuric acid concentrations ranging from 30 to $60 \%$ within the range of reaction temperatures from 40 to $100^{\circ} \mathrm{C}$.

$$
\begin{aligned}
& k_{2}=7.01 \times 10^{14} \exp \\
& \quad[-1.39 \mathrm{C}-31000 /(R T)],
\end{aligned}
$$

where $k_{2}$ is the first-order reaction constant, $C$ sulfuric acid strength expressed by acidity function, $H_{0}, R$ gas constant, $T$ absolute temperature, ${ }^{\circ} \mathrm{K}$.

Yield of Pentose. In Table III, the firstorder reaction constants in hydrolysis of resistant pentosan of white birch wood have been compared with the first-order reaction constants in decomposition of xylose. The values of $k_{r}$, the ratio of $k_{B}$ to $k_{2}$ increases with decrease of the reaction temperature within the range of this experiment. Fig. 16 describes the relation between the value of

TABLE III. Ratio of RAte of PENTOSAN HydRolysis to RATE OF PENTOSE DESTRUCTION

$\begin{array}{ccc}\begin{array}{c}\mathrm{H}_{2} \mathrm{SO}_{4} \\ \text { concn }\end{array} & \begin{array}{c}\text { Temp. } \\ \%\end{array} & \begin{array}{c}\text { Hydrolysis rate constant of pentosan } \\ \text { Destruction rate constant of pentose } \\ k_{r}=k_{B} / k_{2}\end{array} \\ & 80 & 46 \\ 60 & 60 & 360 \\ & 40 & 3000 \\ & 80 & 33 \\ 50 & 60 & 210 \\ & 40 & 1800 \\ 40 & 60 & 29 \\ & 40 & 200 \\ & 80 & 1600 \\ 30 & 60 & 13 \\ & 40 & 85 \\ 10 & 150 & 690 \\ & 100 & 4.5^{*} \\ 1 & 150 & 4.2^{*} \\ & 100 & 3.7^{*}\end{array}$

* Calculated from $k_{2}=1.27 \times 10^{18} \mathrm{C}^{1.07} \exp [-29600 /(R T)]^{10)}$ and $k_{B}=5.57 \times 10^{14} \mathrm{C}^{1.15} \exp [-30900 /(R T)]$

10) T. Kobayashi and Y. Sakai, " Kôbo Riyô Kôgyô ", T. Asai ed., Tokyo, Kyoritsu Shuppansha, "Biseibutsu Kôgaku Kôza," 1957, Vol. IV, p. 191. 
$k_{r}$ and the maximum pentose yield $(\%), Z_{m}$, which is calculated from the equation:

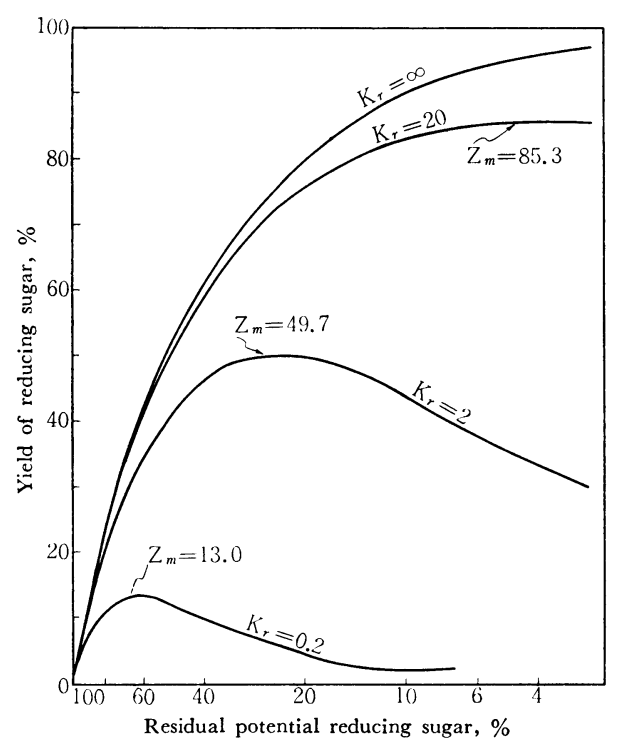

FIG. 16. Yield of Reducing Sugar as A Function of Residual Potential Reducing Sugar for A Variety of $k_{r}$ Values $\left(k_{r}=k_{B} / k_{2}, Z_{m}\right.$ : Maximum Yield of Reducing Sugar).

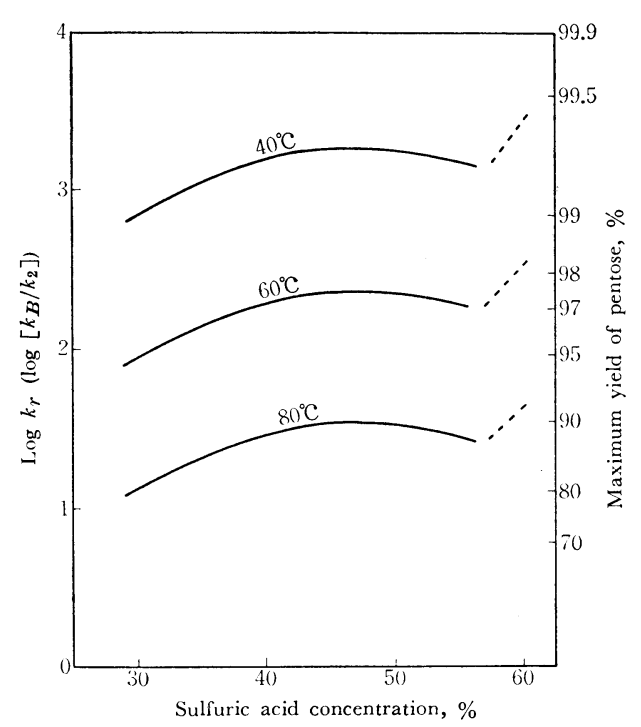

FIG. 17. Value of $k_{r}$ and Maximum Yield of Pentose as a Function of Sulfuric Acid Concentration and Temperature.
$Z_{m}=100 \times k_{r}{ }^{\left.1 /\left(1-\mathrm{k}_{\mathrm{r}}\right) 9,11\right)}$. Fig. 17 shows the relation of sulfuric acid concentration and temperature to $k_{r}$ value and to maximum yield.

When the pre-hydrolysis is carried out in $45 \%$ sulfuric acid at $70^{\circ} \mathrm{C}$, the value of $k_{r}$ becomes 42 and maximum yield of pentose attains $91 \%$ of theory in 125 minutes. The experiment of material balance of pre-hydrolysis of white birch wood using $45 \%$ sulfuric acid was carried out at $70^{\circ} \mathrm{C}$ for 60 minutes and the result is shown in Fig. 18. This result agrees well with the kinetical calculation described above.

The result calculated from the reaction constants presented above shows that when pre-hydrolysis of white birch wood is under-

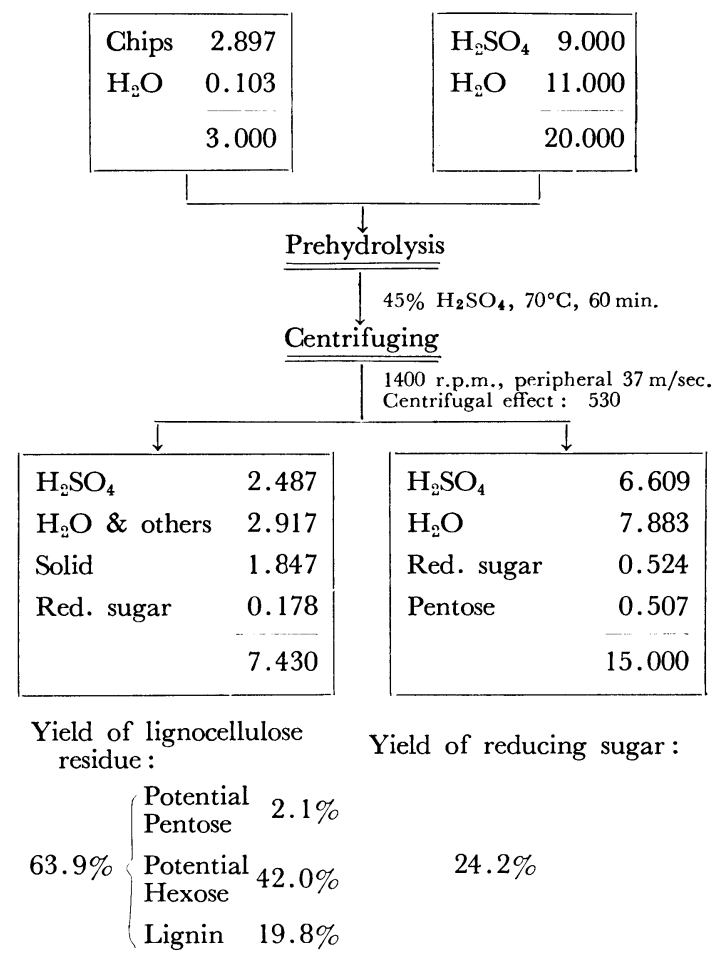

FIG. 18. Material Balance for Prehydrolysis of White Birch (Shirakamba) Wood.

11) F. Thiersch, Z. physik. Chem., 111, 175 (1924). 
taken in $55 \%$ sulfuric acid at $40^{\circ} \mathrm{C}$, pentose yield reaches $99.6 \%$ of the theoretical value in 152 minutes and the loss of hexosan is negligible.

Acknowledgement. The authors wish to express their appreciation to the Grant-in-Aid from Hokkaidô Wood Chemical Industries
Co. Ltd. and the interest given on this work by the members of the Second Meeting on Wood Hydrolysis of FAO Technical Panel on Wood Chemistry held in Tokyo in 1960. They are also grateful to Mr. Tsuyuzaki for his valuable assistance. 